\title{
The correlation between fear of falling and upper extremity muscle strength
}

Bulent Yardimci, MD, Melahat Akdeniz, MD, Tarik Demir, MD.

\begin{abstract}
الأهداف : تحديد العلاقة بين الخوف من السقوط وقوة عضلات الطرف العلوي.

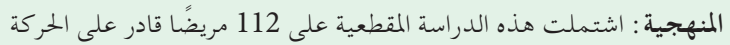

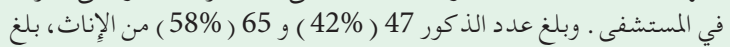

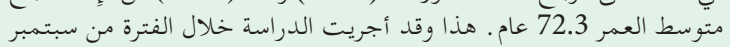

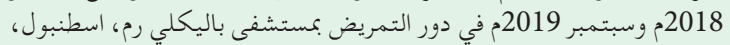

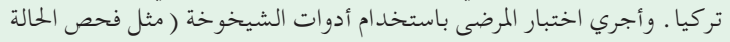

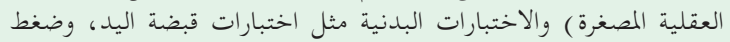
المفتاح، واختبارات الانطلاق لمسافة 6 أمتار .

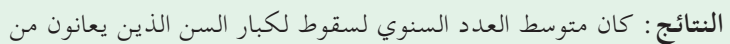
FOF

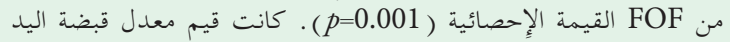

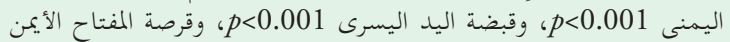

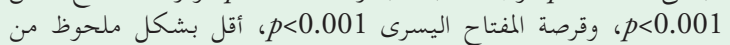
الناحية الإحصائية من أولئك الذين ليس ليس لديهم FOF

الحخلاصة : أن قياس قوة الطرف العلوي يمكن أن يكون معلمة تنبؤية ـFOF.
\end{abstract}

Objectives: To determine the relationship between fear of falling (FOF) and upper extremity muscle strength.

Methods: This cross-sectional study included 112 hospitalized, mobile patients. Forty-seven (42\%) were males and $65(58 \%)$ were females, and the mean age was 72.3. The study was carried out between September 2018 and September 2019 at Balikli Rum Hospital Nursing Homes, Istanbul, Turkey. Patients were tested using geriatric tools (such as MiniMental State Examination) and physical tests such as handgrip, key pinch and 6-meter up and go tests.

Results: The average annual falling number of elderly people with FOF was statistically significantly higher than that in those without FOF $(p=0.001)$. Right handgrip, left handgrip, right key pinch, and left key-pinch mean values in elderly individuals with FOF were statistically significantly lower than those without FOF $(p<0.001, p<0.001, p<0.001, p<0.001$, respectively).

Conclusion: The measurement of upper extremity strength could be a predicting parameter of FOF.

Keywords: fear of falling, muscle strength, nursing home, geriatrics

Saudi Med J 2021; Vol. 42 (4): $411-418$

doi: 10.15537/smj.2021.42.4.20200674

From the Department of Internal Medicine (Yardimci), Istanbul American Hospital; from the Department of Nursing Home (Demir), Balikli Rum Hospital, Istanbul; and from the Department of Family Medicine (Akdeniz), Faculty of Medicine, Akdeniz University, Antalya, Turkey.

Received 20th October 2020. Accepted 23rd February 2021.

Address correspondence and reprint request to: Assoc. Prof. Bulent Yardimci, Istanbul American Hospital, Istanbul, Turkey. E-mail: drbyardimci@gmail.com

ORCID ID: https://orcid.org/0000-0002-0364-8238

Tn recent years, the gradual aging of the world's Ipopulation and their resulting social and economic problems have become one of the most prevalent challenges. According to the World Health Organization's projection, worldwide, the number of people aged over 65 years amounts to 728 million at present and will reach 1 billion in 2030 and 2.5 billion in $2100 .^{1}$ This rapid growth in the aging population brings about certain issues in terms of health care, such as physical and cognitive deficiencies in the population aged 65 years and over, known as the geriatric age group, presenting with special clinical pictures.

One of the most important clinical pictures is falling affecting a large population with varying degrees based on the settings. Approximately one-third of communitydwelling people and three-quarters of nursing home residents aged over 65 years, experience a fall at least 
once a year; ${ }^{2}$ unfortunately, some of them lose their lives due to a fall. ${ }^{3,4}$ Therefore, preventing these falls is of huge importance.

In the older group, fear of falling (FOF) is considered to be an issue as important as falling and is a situation that must undoubtedly be tackled. Fear of falling is defined as 'a lasting concern on falling that can lead to an individual avoiding activities that he/she remains capable of performing, indicating that it is associated with prior fall experience. ${ }^{5}$ However, researches have revealed interesting findings as follows: the FOF rate in older people, who experienced a fall before, is 40\%-73\%, whereas FOF was observed in half of the older people, with no prior fall experience. ${ }^{6}$ Therefore, in addition to being associated with a former falling experience, FOF is also multifactorial. These factors include female gender, older age, insufficient functional capacity, depression, and cognitive impairment. ${ }^{7}$ Parallelism between the falling and FOF risk factors was noted. Programs for the prevention of falling and FOF in nursing home residents are gaining attention and important, as the elderly are considered to be a fragile cohort with a high rate of falling and a FOF rate of $40 \%-70 \%$ which seriously impairs the quality of life. ${ }^{8}$

Assessing the physical performance along with the psychological support of this older cohort is important because FOF is expected to decrease as the physical performance gets better. Objective criteria are required to create the exercise and rehabilitation program for the cohort. Previous studies were concerned with lower extremity strength and balance and the risk group was determined. However, we aimed to identify the correlation between the upper extremity muscle strength and FOF. The idea of this study emerged from the fact that testing is easily conducted and yields objective measurement values. In this study, we evaluated whether determining muscle strength using handgrip and key-pinch tests, as they yield measurable values, and identifying its correlation with FOF would provide guidance when creating rehabilitation programs for older people for overcoming FOF.

Methods. The study was conducted from September 2018 to September 2019 at the Balikli Rum Hospital Nursing Homes, Istanbul, Turkey. The complex consisted of a hospital and nursing home, which has

Disclosure. Authors have no conflict of interests, and the work was not supported or funded by any drug company.
450 beds. The majority of the residents were patients who suffered from a cerebrovascular event, dementia, or chronic illnesses. Exclusion criteria were as follows: patients confined to bed; those walking with assistance; those with neurologic disorders (such as, severe ataxia and epilepsy); those lacking one of the lower extremities; those using a supporting device for walking; those who did not wish to participate in the study. Written consent was obtained from all patients or their guardians for participation in the study. After the exclusion of patients, 112 of a total of 423 patients staying in the nursing home were enrolled in the study group.

One physician, who is in charge of the nursing home, conducted all the patients' examinations and tests. Patients were tested using the mini-mental state examination, geriatric depression scale and LawtonBrody scale. Overall score for each patient were computed according to the patient's results from the tests mentioned above.

Mini-mental state examination is used to measure elderly people's cognitive abilities with a series of tests for orientation, attention, memory, language and visual-spatial skills.

The geriatric depression scale is the result of a 30-item, self-report test using "Yes/No" format, to indicate symptoms of depression in the elderly.

The Lawton-Brody Instrumental Activities of Daily Living (iADL) scale measures the capability of the elderly on 8 specific daily tasks: using the telephone, shopping, food preparation, housekeeping, laundry, transport, medication, and finances.

All these test are widely using and reliable tests in geriatric age group. ${ }^{?}$

To determine the FOF status, the patients were asked the question "Are you afraid of falling?" and were divided into 2 groups according to their "Yes/ No" responses. Moreover, the falls efficacy scale test was conducted for a more detailed evaluation of FOF.

The falls efficacy scale is a 10-point scale that shows a person's confidence on achieving a task without falling. The test to be used on the falls efficacy scale consists of 16 questions. The Falls Efficacy test is accepted as a highly reliable test for measuring FOF. ${ }^{10}$

Subsequently, handgrip and key-pinch tests were conducted on patients. Medical records of the patients were examined, and any diseases found on patients were recorded. Handgrip, key-pinch, and 6-meter up and go tests were conducted on patients, after their body mass indexes were recorded.

Handgrip test. This test was carried out using Jamar Hydraulic Hand Dynamometer (Sammons Preston 
Rolyan, UK). In the preparation step, the patient was seated on a standard chair. Handle distance of the device was adjusted according to the patient's hand size. The patient was told to grip the device with full force with their elbow at a 90-degree angle. Both arms were tested 3 times each. Averages of the 3 tests were calculated for each arm as kilograms.

Key-pinch test. This test followed the same protocol and instructions as the handgrip test. The test was carried out using Jamar Baseline Hydraulic Pinch Gauge (Sammons Preston Rolyan, UK). In this test, the patients were required to squeeze the handle with full force using their thumb and index finger. Both hands were tested 3 times each. Averages of the 3 tests were calculated for each hand as kilograms.

Six-meter up and go test. Patients sat on standard chairs. Patients had their daily clothes on, with the requirement of comfortable shoes. When the physician said "get up", patients stood up, walked the marked 3-meter distance, turned around, walked back to the chair, and sat down. The time between the physician's command and patient sitting down was calculated in minutes.

Statistical analysis. The Statistical Package for Social Sciences for Windows, version 15.0 (IBMCorp, Armonk, NY, USA) was used. Descriptive statistics, including numbers and percentages for categorical variables, mean for numerical variables, and standard deviation, were provided as minimum and maximum values. Comparisons of the numerical variables between the independent 2 groups were conducted using student's t-test when the normal distribution condition was provided and using the Mann-Whitney $U$ test when the normal distribution condition was not provided. Since the parametric test condition could not be provided, more than 2 group analyses were performed using the Kruskal-Wallis test. Subgroup analyses were carried out using the Mann-Whitney $U$ test and interpreted by Bonferroni's correction. Correlations between numerical variables were examined using the Spearman's correlation analysis since the parametric test condition was not achieved. In the cohort, Chi-square test was employed to analyze the ratios. The risk factors were identified by the logistic regression analysis and the cutoff values were determined using receiver operating characteristic (ROC) curve analysis. The statistical alpha significance level was considered as $p<0.05$.

The Ethical Committee and Institutional Review Bilim University Ethics Board for Clinical Research approved the study design with the number 44140529/2015-81.
Results. This study included 112 patients: 47 (42\%) were males and 65 (58\%) females. The sociodemographic characteristics of patients are shown in Table 1. In terms of the FOF question, 52 (46.4\%) patients answered "no," whereas $60(53.6 \%)$ responded with "yes." The female gender ratio and the average age of the elderly people with FOF were statistically significantly higher than those without FOF $(p=0.008$; $p<0.001$, respectively) (Table 1 ).

The average annual number of falls in elderly individuals with FOF was statistically significantly higher than in those without FOF $(p=0.001)$. The mini-mental state examination, Lawton-Brody scale, right handgrip, left handgrip, right key pinch, and left key-pinch mean values in elderly individuals with FOF were statistically significantly lower than in those without FOF $(p=0.009 ; p=0.001 ; p<0.001 ; p<0.001$; $p<0.001 ; p<0.001$, respectively). The average of 6 -meter stand up and walk test and falls efficacy scale values in the elderly with FOF was statistically significantly higher than those without FOF (for both, $p<0.001$ ) (Table 2).

The falls efficacy scale values were statistically significantly positively correlated with age $(r=0.297$, $p=0.002)$ and the 6-meter stand up and walk test $(\mathrm{r}=0.494, \quad p<0.001)$ and negatively with the mini-mental test $(\mathrm{r}=-0.220, p<0.020)$, Lawton-Brody scale $(\mathrm{r}=-0.369, p<0.001)$ right handgrip $(\mathrm{r}=-0.685$, $p<0.001)$, left handgrip $(\mathrm{r}=-0685, p<0.001)$ right key pinch $(p=-0.522, p<0.001)$, and left key-pinch $(\mathrm{r}=-0.473, p<0.001)$ values.

The mean of female gender in the falls efficacy scale was statistically significantly higher than that of the male gender $(p<0.001)$. Regarding the marital status, there was a statistically significant difference in the falls efficacy scale means $(p=0.008)$. The falls efficacy scale mean of widows/widowers and married $(p=0.004)$ participants was statistically significantly higher than that of single participants $(p=0.011)$ (Table 3).

The lower extremity strength determined by the 6-meter stand up and walk test was statistically significantly negatively correlated with the hand grip and key-pinch measurements (all comparisons, $p<0.001)$. The results are shown in Table 4.

For the risk factors of falling, in the multivariate regression analysis, the annual number of falls and the right and left hand grip levels were the most statistically significant factors $(p=0.004 ; p=0.022 ; p=0.049$, respectively) (Table 5 ).

In terms of the ROC curve analysis for the cut-off values in those without falling risk, a cut-off value of 
Fear of falling and muscle strength ... Yardimci et al

Table 1 - Sociodemographic characteristics: total and with or without fear of falling.

\begin{tabular}{|c|c|c|c|c|c|c|}
\hline \multirow[b]{2}{*}{ Characteristics } & \multirow{2}{*}{$\begin{array}{c}\text { Total } \\
\operatorname{Med} \pm \text { SD }(\min -\max )\end{array}$} & \multicolumn{2}{|c|}{ No } & \multicolumn{2}{|c|}{ Yes } & \multirow[b]{2}{*}{$P$-value } \\
\hline & & Med \pm SD & $\begin{array}{l}\text { Min-Max } \\
\text { (median) }\end{array}$ & $\operatorname{Med} \pm \mathrm{SD}$ & $\begin{array}{l}\text { Min-Max } \\
\text { (median) }\end{array}$ & \\
\hline Age & $72.3 \pm 11.2(43-97)$ & $69.3 \pm 10.7$ & $43-92(67.5)$ & $74.9 \pm 11.1$ & 43-97 (77) & 0.008 \\
\hline Height & $164.1 \pm 10.6(145-188)$ & $166.4 \pm 11.2$ & $146-188(167)$ & $160.8 \pm 9.1$ & $145-175(160)$ & 0.146 \\
\hline Weight & $74.9 \pm 21.0(27-130)$ & $75.0 \pm 18.6$ & $40-116(80)$ & $74.7 \pm 24.9$ & $27-130(70)$ & 0.968 \\
\hline Body mass index & $28.2 \pm 6.5(12.8-56.4)$ & $28.7 \pm 6.6$ & $16.6-56.4(27.8)$ & $27.8 \pm 6.4$ & $12.8-48.3(27.5)$ & 0.477 \\
\hline \multicolumn{7}{|l|}{ Gender } \\
\hline Male & $47(42.0)$ & 34 & 65.4 & 13 & 21.7 & $<0.001$ \\
\hline Female & $65(58.0)$ & 18 & 34.6 & 47 & 78.3 & \\
\hline \multicolumn{7}{|l|}{ Educational level } \\
\hline Primary education & $64(57.1)$ & 25 & 48.1 & 39 & 65.0 & 0.066 \\
\hline Secondary education & $31(27.7)$ & 15 & 28.8 & 16 & 26.7 & \\
\hline University & $17(15.2)$ & 12 & 23.1 & 5 & 8.3 & \\
\hline \multicolumn{7}{|l|}{ Marital status } \\
\hline Single & $31(27.7)$ & 18 & 34.6 & 13 & 21.7 & 0.293 \\
\hline Widow(er) & $41(36.6)$ & 18 & 34.6 & 23 & 38.3 & \\
\hline Married & $40(35.7)$ & 16 & 30.8 & 24 & 40.0 & \\
\hline \multicolumn{7}{|l|}{ Spouse status } \\
\hline Separated & $35(31.3)$ & 16 & 30.8 & 19 & 31.7 & 0.246 \\
\hline Together & $16(14.3)$ & 10 & 19.2 & 6 & 10.0 & \\
\hline Not married & $24(21.4)$ & 13 & 25.0 & 11 & 18.3 & \\
\hline Deceased & $37(33.0)$ & 13 & 25.0 & 24 & 40.0 & \\
\hline \multicolumn{7}{|l|}{ Additional disease } \\
\hline Diabetes mellitus & $22(19.6)$ & 10 & 19.2 & 12 & 20.0 & 0.919 \\
\hline Hypertension & $28(25.0)$ & 13 & 25.0 & 15 & 25.0 & 1.000 \\
\hline Cardiac disease & $12(10.7)$ & 5 & 9.6 & 7 & 11.7 & 0.726 \\
\hline Bronchial asthma-COPD & $10(8.9)$ & 3 & 5.8 & 7 & 11.7 & 0.334 \\
\hline Hypothyroidism & $2(1.8)$ & 0 & 0.0 & 2 & 3.3 & 0.498 \\
\hline Hyperthyroidism & $2(1.8)$ & 0 & 0.0 & 2 & 3.3 & 0.498 \\
\hline Hypercholesterolemia & $1(0.9)$ & 0 & 0.0 & 1 & 1.7 & 1.000 \\
\hline Arthritis & $1(0.9)$ & 0 & 0.0 & 1 & 1.7 & 1.000 \\
\hline Renal insufficiency & $1(0.9)$ & 1 & 1.9 & 0 & 0.0 & 0.464 \\
\hline Depression & $3(2.7)$ & 2 & 3.8 & 1 & 1.7 & 0.596 \\
\hline Osteoporosis & $5(4.5)$ & 3 & 5.8 & 2 & 3.3 & 0.662 \\
\hline Cancer & $3(2.7)$ & 3 & 5.8 & 0 & 0.0 & 0.097 \\
\hline Other & $3(2.7)$ & 2 & 3.8 & 1 & 1.7 & 0.596 \\
\hline \multicolumn{7}{|l|}{ Number of additional disease } \\
\hline None & $30(26.8)$ & 15 & 28.8 & 15 & 25.0 & 0.848 \\
\hline One & $72(64.3)$ & 33 & 63.5 & 39 & 65.0 & \\
\hline Two or three & $10(8.9)$ & 4 & 7.7 & 6 & 10.0 & \\
\hline
\end{tabular}

Values are presented as number and percentages (\%). COPD: chronic obstructive pulmonary disease 
Fear of falling and muscle strength ... Yardimci et al

Table 2 - Correlation between fear of falling. Physical capabilities and geriatric tools.

\begin{tabular}{|c|c|c|c|c|c|c|}
\hline \multirow[b]{2}{*}{ Test } & \multirow{2}{*}{$\begin{array}{c}\text { Total } \\
\text { Med. } \pm \text { SD (Min-Max) }\end{array}$} & \multicolumn{2}{|c|}{ No } & \multicolumn{3}{|c|}{ Yes } \\
\hline & & $\operatorname{Med} \pm S D$ & $\begin{array}{c}\text { Min-Max } \\
\text { (median) }\end{array}$ & $\mathrm{Med} \pm \mathrm{SD}$ & Min-Max (median) & P-value \\
\hline Annual number of falls & $15.9 \pm 8.0(0-33)$ & $0.29 \pm 0.46$ & $0-1(0)$ & $0.92 \pm 1.48$ & $0-10(1)$ & 0.001 \\
\hline Mini Mental Test & $13.6 \pm 5.8(0-26)$ & $18.2 \pm 6.8$ & $0-33(18)$ & $13.9 \pm 8.5$ & $0-30(14.5)$ & 0.009 \\
\hline Geriatric Depression Scale & $2.74 \pm 2.87(0-8)$ & $13.4 \pm 4.4$ & $0-22(13)$ & $13.7 \pm 6.9$ & $0-26(15)$ & 0.241 \\
\hline Lawton-Brody Scale & $0.63 \pm 1.16(0-10)$ & $3.81 \pm 3.04$ & $0-8(4)$ & $1.82 \pm 2.38$ & $0-8(1)$ & 0.001 \\
\hline 6 meter stand up and walk test & $18.9 \pm 13.4(5-63)$ & $14.6 \pm 10.1$ & $5-60(12)$ & $22.6 \pm 14.8$ & $8-63(17.5)$ & $<0.001$ \\
\hline Right handgrip & $15.3 \pm 9.9(0.5-48)$ & $21.7 \pm 9.0$ & $10-48(20)$ & $9.7 \pm 6.7$ & $0.5-32(10)$ & $<0.001$ \\
\hline Left handgrip & $14.5 \pm 9.8(0.5-50)$ & $20.9 \pm 9.5$ & $8-50(19)$ & $8.9 \pm 6.1$ & $0.5-30(8)$ & $<0.001$ \\
\hline Right key pinch & $4.78 \pm 2.28(0.5-12.5)$ & $6.09 \pm 2.13$ & $3-12.5(5.25)$ & $3.64 \pm 1.74$ & $0.5-10.5(3.75)$ & $<0.001$ \\
\hline Left key pinch & $4.43 \pm 2.13(0.5-12.5)$ & $5.59 \pm 2.27$ & $1-12.5(5)$ & $3.42 \pm 1.37$ & $0.5-8(3.25)$ & $<0.001$ \\
\hline Falls Efficacy Scale & $42.7 \pm 27.1(10-96)$ & $18.1 \pm 9.9$ & $10-51(14)$ & $64.1 \pm 17.4$ & $15-96(65.5)$ & $<0.001$ \\
\hline
\end{tabular}

Table 3 - Falls Efficacy Scale means in sociodemographic characteristics.

\begin{tabular}{lccc}
\hline Characteristics & Mean \pm SD & Min-Max (median) & $P$-value \\
\hline Gender & & & \\
$\quad$ Male & $29.6 \pm 22.5$ & $10-80(18)$ & $<0.001$ \\
Female & $52.2 \pm 26.4$ & $10-96(55)$ & \\
Educational level & & & \\
$\quad$ Primary education & $44.4 \pm 26.9$ & $10-92(49.5)$ & 0.211 \\
Secondary education & $45.7 \pm 27.9$ & $10-96(42)$ & \\
University & $31.1 \pm 25.0$ & $10-80(19)$ & \\
Marital status & & & 0.008 \\
Single & $31.4 \pm 24.6$ & $10-88(19)$ & \\
Widow(er) & $47.1 \pm 27.4$ & $10-96(52)$ & \\
$\quad$ Married & $46.9 \pm 26.9$ & $10-93(50)$ & \\
Spouse status & & & \\
Separated & $44.6 \pm 28.3$ & $10-93(53)$ & \\
Together & $35.9 \pm 25.6$ & $10-84(28)$ & \\
Not married & $33.4 \pm 25.6$ & $10-88(24.5)$ & \\
Deceased & $49.9 \pm 26.2$ & $10-96(54)$ & \\
Number of additional diseases & & & \\
None & $37.1 \pm 26.8$ & $10-90(29)$ & 0.303 \\
One & $44.2 \pm 27.2$ & $10-96(46.5)$ & \\
Two or three & $48.9 \pm 27.7$ & $15-85(50)$ & \\
& & &
\end{tabular}

Single versus (vs.) widow(er): $p=0.004$, single vs. married: $p=0.011$, widow(er) vs. married: $p=0.821$

Table 4 - Correlation between 6-meter stand up and walk test and upper extremity muscle strength tests.

\begin{tabular}{lcc}
\hline Test & $\mathbf{r}$ & $P$-value \\
\hline Right handgrip & -0.526 & $<0.001$ \\
Left handgrip & -0.457 & $<0.001$ \\
Right key pinch & -0.494 & $<0.001$ \\
Left key pinch & -0.423 & $<0.001$ \\
\hline
\end{tabular}


Table 5 - Falling risk factors, multivariate regression analysis, modeling, and backward method.

\begin{tabular}{|c|c|c|c|}
\hline Variables & $P$-value & OR & $95 \% \mathrm{CI}$ \\
\hline \multicolumn{4}{|l|}{ Enter method } \\
\hline Age & 0.839 & 0.993 & $0.928-1.062$ \\
\hline Gender & 0.624 & 1.445 & $0.331-6.306$ \\
\hline Educational level & 0.352 & 1.569 & $0.607-4.052$ \\
\hline Spouse status & 0.722 & 1.101 & $0.648-1.869$ \\
\hline Mini-mental test & 0.459 & 0.961 & $0.863-1.069$ \\
\hline $\begin{array}{l}\text { Geriatric Depression } \\
\text { Scale }\end{array}$ & 0.654 & 1.028 & $0.911-1.160$ \\
\hline Lawton-Brody scale & 0.911 & 0.987 & $0.781-1.247$ \\
\hline Annual number of falls & 0.005 & 5.119 & $1.647-15.907$ \\
\hline $\begin{array}{l}6 \text {-meter stand up and } \\
\text { walk test }\end{array}$ & 0.201 & 1.040 & $0.979-1.104$ \\
\hline Right handgrip & 0.332 & 0.922 & $0.783-1.086$ \\
\hline Left handgrip & 0.109 & 0.870 & $0.733-1.032$ \\
\hline Right key pinch & 0.434 & 0.761 & $0.384-1.508$ \\
\hline Left key pinch & 0.831 & 1.083 & $0.522-2.246$ \\
\hline \multicolumn{4}{|l|}{ Backward method } \\
\hline Annual number of falls & 0.004 & 4.190 & $1.591-11.035$ \\
\hline Right handgrip & 0.022 & 0.865 & $0.764-0.979$ \\
\hline Left handgrip & 0.049 & 0.877 & $0.770-0.999$ \\
\hline
\end{tabular}

$14.5 \mathrm{~kg}$ and over was determined for the right hand grip (sensitivity, $80.8 \%$; specificity, $83.3 \%$ ) and $13.5 \mathrm{~kg}$ and over for the left hand grip (sensitivity, $80.8 \%$; specificity, $81.7 \%$ ) (Figure 1).

Discussion. The outcomes of this study reveal that the muscle strength in older people with FOF is weaker and that the handgrip and key-pinch test values are lower than those without FOF. Besides, those with FOF have completed the 6-meter stand up and walk test in a longer time.

Fear of falling is a multifactorial condition affected by physical and psychological risk factors, which is challenging to measure. ${ }^{11,12}$ The question of whether there is any fear or not is the most simple evaluation of FOF. In this study, we have used the falls efficacy scale in addition to this basic question. Finally, we determined that those with a high fall efficacy scale value, that is those who are less self-confident regarding falling, answered "yes" to the question on FOF. According to these results, this basic question seems to be sufficient to be used in daily practice.

A previous study examined FOF in communitydwelling older adults, in which FOF was interestingly less than in those living in nursing homes. ${ }^{13}$ Although nursing homes are designed for the older population with special adjustments to reduce falls such as bed

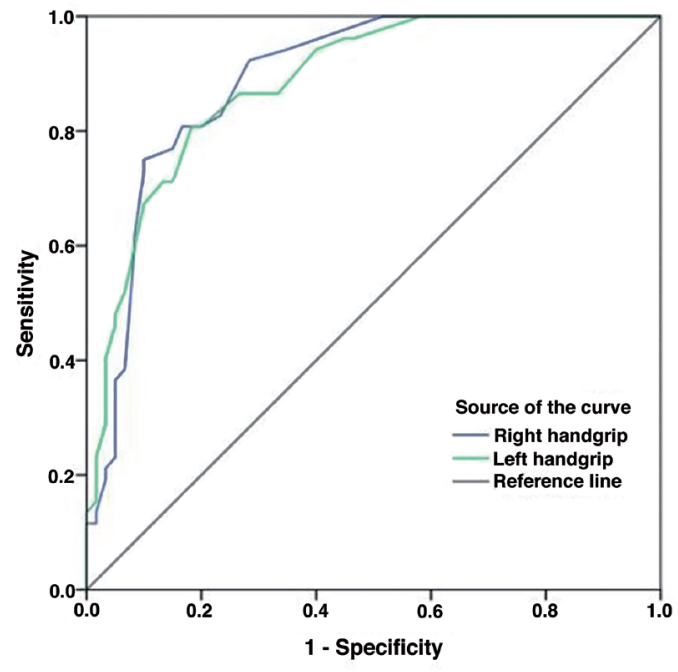

\begin{tabular}{|l|c|c|c|c|}
\hline Test results variable(s) & AUC & SE & \multicolumn{2}{|c|}{$95 \%$ CI } \\
\hline Right handgrip & 0.890 & 0.031 & 0.829 & 0.951 \\
\hline Left handgrip & 0.884 & 0.031 & 0.824 & 0.945 \\
\hline
\end{tabular}

Figure 1 - Receiver operating characteristic curve analysis for the intersection values of the right and left handgrip tests in determining those without the probability of fall risk.

heights, non-slippery grounds, adequate lighting, and auxiliary staff, FOF is found to be higher. Another important factor is the low self-esteem of nursing home residents, which has not been fully explored. It has been observed that the lack of social relationships between community-dwelling adults and their families and friends, especially in rural areas or small towns,

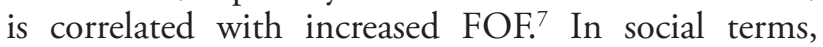
identifying to what extent the educational status and marriage affect FOF is important. We have not detected any direct correlation between educational status and FOF. On the other hand, we have observed that the falls efficacy scale values of married people and widows/ widowers are higher than those of single people; that are FOF is less. Future studies are warranted to further explore why marital status affects FOF.

In this study, those with a good mini-mental state exam score had less FOF rate. Moreover, participants with a high Lawton-Brody scale values had less FOF rate; those with a good physical performance had higher self-confidence and consequently, their FOF and the falling rates were lower. These results were in line with those of previous studies. ${ }^{12,13}$

Similarly, in women of older age, FOF was high, due to the fact that they had more problems in terms of carrying out their daily activities and maintaining their muscle strength and balance, leading to an increase 
in both falling and FOF rates. Besides, FOF is also high in the older male cohort, and some studies used accelerometers to objectively measure physical activities in men. ${ }^{14,15}$

In this study, our main focus was to determine the correlation of muscle strength with FOF. Many studies have been conducted on the significance of balance, walking, and muscle strength in FOF; ${ }^{16}$ however, in a great part of these studies, walking, balance, and lower extremity strength were used as measuring criteria. In our study, the 6-meter stand up and walk test was conducted, and in those with FOF, the duration to complete the test was longer. ${ }^{17,18}$ However, since our main purpose is to determine whether there is any correlation between the upper extremity muscle strength and FOF, the hand grip and key-pinch tests were employed in our study. The finding of the tests revealed the following: those with high scores in the hand grip and key-pinch tests had lower FOF rates. Moreover, in FOF, the lack of upper extremity muscle strength went hand in hand with lower extremity weakness. As a result, the evaluation of the lack of upper extremity muscle strength using basic methods suggests that they could be used as follow-up criteria in the evaluation and rehabilitation of FOF.

Physical frailty caused by old age significantly contributes to the development of FOF. Many studies demonstrate that FOF results in the loss of selfconfidence, restrictions in physical activity and social participation, physical frailty, increased fall risk, and loss of independence. ${ }^{19,20}$

An important question is whether increased physical performance minimizes FOF. We have concluded that FOF increases with decreased muscle strength. Therefore, we believe that muscle-strengthening exercises could result in reducing FOF in the elderly people cohort. It has been observed that communitybased tai chi, home-based exercises, and multifactorial physical intervention toward minimizing falls at home have reduced FOF rates. ${ }^{21,22}$ It is highly probable that muscle-strengthening exercise programs applied with nursing home residents lessened FOF and, consequently, the fall rates, in turn increasing their quality of life as falls are a major problem in the elderly population. In the follow-up of these patients, the handgrip test may be used for objectively assessing physical activity. Prospective studies are required to determine to what extent will FOF be reduced with increased handgrip test values after applying exercise programs in nursing homes.

Study limitations. The major limitation of this study is that the data is observational due its cross-sectional design. Therefore, a cause and effect relationship cannot be established.

In conclusion, the measurement of upper extremity strength is a parameter used in evaluating FOF. In agreement with previous studies, our study has shown that the upper extremity strength was reduced in those with FOF. In light of all this information, we suggest that muscle strength is one of the significant indicators of FOF.

Acknowledgment. The authors gratefully acknowledge Enago (www.enago.com) for English language editing.

\section{References}

1. Department of Economic and Social Affairs. World Population Prospect 2019. [Updated 2019; Accessed 2020 January 10]. Avaliable from URL: https://population.un.org/wpp/ Download/Probabilistic/Population/

2. Tinetti ME. Clinical practice. Preventing falls in elderly persons. N Engl J Med 2003; 348: 42-49.

3. Gschwind YJ, Kressig RW, Lacroix A, MuehlbauerT, Pfenninger B, Granacher U. A best practice fall prevention exercise program to improve balance, strength/power, and psychosocial health in older adults: study protocol for a randomized controlled trial. BMC Geriatr 2013; 13: 105.

4. Hale LA, Waters D, Herbison P. A randomized controlled trial to investigate the effects of water-based exercise to improve falls risk and physical function in older adults with lower-extremity osteoarthritis. Arch Phys Med Rehabil 2012; 93: 27-34.

5. Tinetti ME, Powell L. Fear of falling and low self-efficacy: a case of dependence in elderly persons. J Gerontol 1993; 48: 35-38.

6. Murphy SL, Dubin JA, Gill TM. The development of fear of falling among community-living older women: predisposing factors and subsequent fall events. J Gerontol A Biol Sci Med Sci 2003; 58: M943-M947.

7. Lavedán A, Viladrosa M, Jürschik P, Botigué T, Nuín C, Masot $\mathrm{O}$, et al. Fear of falling in community-dwelling older adults: A cause of falls, a consequence, or both? PLoS One 2018; 13: 1-14.

8. Lach HW, Parsons JL. Impact of fear of falling in long term care: An integrative review. J Am Med Dir Assoc 2013; 14 : 573-577.

9. Yardimci B, Aran SN, Ozkaya I, Aksoy SM, Demir T, Tezcan G, et al. The role of geriatric assessment tests and anthropometric measurements in identifying the risk of falls in elderly nursing home residents. Saudi Med J 2016; 37: 1101-1108.

10. Mehdizadeh M, Martinez-Martin P, Habibi SA, Fereshtenejad SM, Abasi A, Khaton JN, et al. Reliability and Validity of Fall Efficacy Scale-International in people with Parkinson's disease during on- and off-drug phases. Parkinsons Dis 2019; 2: 1-7.

11. Lee S, Oh E, Hong GS. Comparison of factors associated with fear of falling between older adults with and without a fall history. Int J Environ Res Public Health 2018; 15: 982.

12. Bjerk M, Brovold T, Skelton DA, Bergland A. Associations between health-related quality of life, physical function and fear of falling in older fallers receiving home care. BMC Geriatrics 2018; 18: 253 . 
13. Tomita Y, Arima K, Tsujimoto R, Kawashiri S, Nishimura T, Mizukami S, et al. Prevalence of fear of falling and associated factors among Japanese community-dwelling older adults. Medicine 2018; 97: 4.

14. Jefferis BJ, Iliffe S, Kendrick D, Kerse N, Trost S, Lennon LT, et al. How are falls and fear of falling associated with objectively measured physical activity in a cohort of community-dwelling older men? BMC Geriatr 2014; 14: 114.

15. Patil R, Uusi-Rasi K, Kannus P, Karikanta S, Sievanen H. Concern about falling in older women with a history of falls: associations with health, functional ability, physical activity and quality of life. Gerontology 2014; 60: 22-30.

16. Panel on Prevention of Falls in Older Persons AGS, British Geriatrics S. Summary of the updated American Geriatrics Society/British Geriatrics Society clinical practice guideline for prevention of falls in older persons. J Am Geriatr Soc 2011; 59: 148-157.

17. Rochat S, Büla CJ, Martin E, Seematter-Bagnoud L, Karmaniola A, Aminian K. What is the relationship between fear of falling and gait in well-functioning older persons aged 65 to 70 years? Arch Phys Med Rehabil 2010; 91: 879.
18. Tomita Y, Arima K, Tsujimoto R, Kawashiri SY, Nishimura T, Mizukami S, et al. Prevalence of fear of falling and associated factors among Japanese community-dwelling older adults. Medicine (Baltimore) 2018; 97: e9721.

19. Yardley L, Smith H. A prospective study of the relationship between feared consequences of falling and avoidance of activity in community-living older people. Gerontologist 2002; 42: $17-23$.

20. Delbaere K, Crombez G, Vanderstraeten G, Willems T, Cambier D. Fear-related avoidance of activities, falls and physical frailty. A prospective community-based cohort study. Age Ageing 2004; 33: 368-373.

21. Zijlstra GR, Van Haastregt JC, Van Rossum E, Van Eijk JT, Yardley L, Kempen GI. Interventions to reduce fear of falling in community-living older people: a systematic review. $\mathrm{J} \mathrm{Am}$ Geriatr Soc 2007; 55: 603-615.

22. Phelan E, Mahoney J, Voit JC, Stevens JA. Assessment and management of fall risk in primary care settings. Med Clin North Am 2015; 99: 281-293. 